\title{
JOVENS E O FAZER TEATRAL: CONTRIBUIÇÕES AOS SEUS PROCESSOS DE SOCIALIZAÇÃO, CONHECIMENTO DE SI E AUTONOMIA.
}

\section{Resumo:}

$\mathrm{O}$ presente trabalho apresenta resultados da pesquisa de mestrado que investigou as contribuições do fazer teatral à socialização, autonomia e individuação de jovens em espaços de educação não escolar. A pesquisa tem como sujeitos jovens com idades ente 15 e 29 anos, participantes de curso de iniciação em teatro desenvolvidas por uma organização não governamental inserida em espacialidade urbana da região do nordeste do estado de São Paulo. O estudo, de natureza qualitativa, utiliza aportes das áreas das Ciências Sociais, Teatro e Educação. Os resultados obtidos até aqui apontam diversificação dos processos de socialização, de autonomia e individuação, dos jovens, constituindo-se em uma prática educativa que vai além da transmissão de técnicas, saberes e conhecimentos próprios da linguagem teatral.

Palavras-chave: Jovens; Fazer Teatral; Teatro; Socialização; Educação não escolar.

\begin{abstract}
:
This paper presents partial results of the research that focuses on the contributions of the theatrical creative process to the socialization, individualization and autonomy of young people in educational spaces outside of formal schooling. The study focuses on young people, aged between 15 and 29, who attend introductory theater classes in a non-governmental organization located at a urban spaciality in the northeastern region of the State of São Paulo. The study is based on qualitative data grounded on contributions from the areas of Social Sciences, Theater and Education. The results so far suggest a diversification of the socialization, individualization and autonomy processes of young people, indicative of a educational practice that goes beyond the transmission of theater techniques and the theatrical language.
\end{abstract}

Keywords: Young People; Theater ; Socialization ; Non-scholar education 


\section{Introdução}

O trabalho apresenta resultados da pesquisa de mestrado sobre as contribuições das atividades formativas na linguagem teatral aos processos de socialização secundária (BERGER \& LUCKMANN) e individuação (MARTUCCELLI) aos jovens que freqüentam tais atividades em espaços de educação não formal e os significados atribuídos por esses mesmos jovens a formação e experiências ali vivenciadas. A pesquisa traz diálogo entre os relatos desses jovens e referenciais teóricos das áreas da Sociologia da Educação, das Artes e Psicologia.

\section{Metodologia}

O estudo filia-se ao conjunto de pesquisas de natureza qualitativa, as quais, segundo Heloisa de Souza Martins (2004), ao tomar "unidades sociais investigadas como totalidades", impõem ao pesquisador "um exame intensivo". Foram adotados dois procedimentos metodológicos combinados: atividades de observação direta e livre, com registro de anotações em caderno de campo, das atividades educativas do fazer teatral vivenciadas pelos jovens; e a realização de "entrevistas compreensivas”, sobre as quais diz Vitor Sérgio Ferreira (2014),

trata-se de uma técnica qualitativa de recolha de dados que articula formas tradicionais de entrevista semidiretiva com técnicas de entrevista de natureza mais etnográfica, na tentativa de evitar quer o dirigismo do modelo de questionário aberto, quer o laissez-faire da entrevista não diretiva. (FERREIRA, 2014, p. 981).

\section{O fazer teatral e o jogo: autoconhecimento e reflexividade.}

Para Augusto Boal (2002), o teatro seria ferramenta vital para o autoconhecimento, e reflexividade, pois "o teatro nasce quando o ser humano descobre que pode observar-se a si mesmo: ver se em ação, ou seja, o ser humano "descobre que pode ver-se no ato de ver-se em situação" (id: p. 27).

Em diferentes autores (SLADE, 1978; COURTNEY, 2003; BERGER \& LUCKMAN, 1994; LOPES, 1989; HUIZINGA, 1980; DESGRANGES, 2011) encontramos a categorização do jogo como elemento vital do fazer teatral, citado como jogo dramático, jogo de improvisação etc. As primeiras experiências de jogo estariam localizadas na infância, porém ele acompanharia o indivíduo até a fase adulta. Segundo Courtney (2003):

a criança em desenvolvimento tem um primeiro ano de vida que é essencialmente motor; e então- com algumas crianças isso ocorre de maneira súbita- ocorre a mudança: passa a jogar, desenvolve seu humor, finge ser ela mesma ou outro alguém. (...) este é o desenvolvimento especifico que difere o homem de outras 
criaturas vivas- a habilidade para compreender o ponto de vista de outrem (COURTNEY 2003, p. 21- grifos nossos).

\section{Resultados:}

Os depoimentos dos jovens permitem extrair algumas contribuições que o curso de iniciação em teatral do IRC exerce em suas experiências diárias ou cotidianas. Cito duas: no campo das relações com a alteridade, o reconhecimento e aceitação do outro:

Tem por que lá no curso... são pessoas (risos). Cada pessoa é de um jeito e você tem que aprender a conviver com tipos diferentes de pessoas. (...)tem que ter uma certa paciência com essa pessoa e tem que exigir dessa pessoa também! E é muito difícil isso ai né?Principalmente o trabalho de convivência com pessoas isso acho que mudou todo mundo ali! Me ajudou pra caramba! (SOFIA).

E também nas questões relativas ao corpo: noções que compreendem desde o autoconhecimento até a exploração de seus limites e potencialidades:

Um autoconhecimento muito grande e depois que você aprende as técnicas de teatro, que você vai vendo o que você consegue fazer, coisa que nem imaginava que conseguiria fazer. (SOFIA)

e... também em relação... acho que não tem muito a ver com essa pergunta... em relação ao pudor ao corpo. Que isso eu já não tinha muito agora eu já não tenho nenhum! Corpo é carne, todo mundo tem... é tudo igual! E não tem esse negócio, de... (gesto de recusa do toque) (risos), não tem mais esse negócio de pudor. Que é uma coisa simples! Coisa que a gente vê com muita malícia, que não tem motivo prá ver com malícia. (HELENA)

\section{Considerações finais}

O estudo aponta que o teatro pode propiciar aos jovens um espaço/tempo de trocas simbólicas, de construção coletiva de signos, protagonizado por diferentes subjetividades que encontram no jogo o objetivo de construírem algo juntos. Possibilidades enriquecedoras, sobretudo na juventude, fase que exige dos indivíduos processos de formação, experimentação, escolhas, reversibilidade das escolhas, processos de iniciação e formulação de projetos para o presente e para o futuro (FABRINNI \& MELLUCCI, 1992). 


\section{REFERÊNCIAS}

BOAL, Augusto. O arco-íris do desejo. Civilização Brasileira. Rio de Janeiro. 2002.

BERGER, Peter; LUCKMANN, Thomas. A construção social da realidade. Petrópolis: Vozes, 1976.

COURTNEY, Richard. Jogo, teatro e pensamento: as bases intelectuais do teatro na educação. São Paulo: 1980.

DeSGrangeS, Flávio. Pedagogia do Teatro: Provocações e Dialogismo. São Paulo: 3 ed. Hucitec: edições Mandacaru, 2011.

FABRINI, A; MELUCCI, A. Lètá dell oro: adolescenti tra sogno ed esperienza. Milano: Goangiacomo Feltrinelli Editores, 1992.

FERREIRA, V. S. Artes e manhas da entrevista compreensiva. Saúde e Sociedade, 23 (3), 979-992. 2014

HUIZINGA, Johan. Homo Ludens. 4.ed São Paulo: Perspectiva, 2001.

LOPES, Joana. Pega Teatro. 1.ed.São Paulo: Papirus, 1989.

MARTINS. Heloisa Helena. Metodologia qualitativa de pesquisa. in: Universidade de São Paulo - Educação e Pesquisa. São Paulo, v. 30, n. 2, p. 289-300, maio/ago. 2004.

MARTUCCELLI, Danilo. Lecciones de sociologia del individuo, Lima, Peru: Pontificia Universidade Catolica del Peru, Departamento de Ciencias Sociales, 2012.

NAKANO, Marilena \& ALMEIDA, Elmir. Reflexões acerca da busca de uma nova qualidade da educação: relações entre juventude, educação e trabalho. In: Educação \& Sociedade, Campinas, vol. 28, n. 100 - Especial, p. 1085-1104, out. 2007 
PAIS, José Machado. A construção sociológica da juventude- alguns contributos. Análise Social vol. XXV, 1990 .

SPOSITO, M. (coord.). Estado da arte sobre juventude na pós-graduação brasileira: educação, ciências sociais e serviço social (1999-2006), 2 volume. Belo Horizonte, MG:Argvmentvm, 2009, v.2. 